\title{
노르웨이 대외원조 개관
}

\section{I . 노르웨이 원조 개요}

\section{1. 원조목적}

모르웨이의 개발원조 정책기조는 '포괄적 개발정 책, 1) '빈곤퇴치를 위한 노르웨이 정부 행동계획 (2002)', '개발원조정책 백서(2004)' 등 일련의 정책보고서를 통해 강화되고 있음.

- 빈곤퇴치(Poverty reduction)가 중심목표임. 동 목표달성을 위해 새천년개발목표(MDGs)를 준 거지표로 삼고 있음.

-이와 관련, 노르웨이 정부는 타 공여기관 및 $\mathrm{NGO}$ 등과의 정책대화에서 범세계적 파트너십을 구축하는 것을 주요 목표 중 하나로 삼고 있음.
대외원조법 제정 여부

- 현재 별도의 법률은 제정되어 있지 않으며 '노르 웨이 대외관련법(Law on the Norwegian Foreign Service)' 에 ODA 근거 규정이 있는 외 에 매년 정부가 의회에 제출하는 budget proposal 및 교육 · 환경 - 아동 등 각 분야별로 정부에서 작성하는 strategy paper 등이 ODA 집행의 준거규정이 되고 있음.

\section{2. 원조정책}

모르웨이는 지원대상국을 주요 지원대상국 및 기 타 지원대상국 등 2 개 그룹으로 분류

-주요 지원대상국(main partner countries):방

\footnotetext{
1) 동 보고서에서는 빈곤퇴치를 위해 다음 4 개 분야에서의 혁신이 필요함을 밝힘.

-국제개발협력 프레임웍(무역, 기술이전, 부채탕감, 정책일관성)

- 거버넌스(수원국 스스로의 내부적 관리역량 개선의지 필요)

-국제개발원조(수원국 주인의식 고양 및 개발원조의 양적, 질적 개선)

-개발재원동원(특히, 민간부문과 시민사회 역량 활용)
} 
글라데시, 말라위, 모잠비크, 네팔, 탄자니아, 우 간다, 잠비아 (7개국)

-기타 지원대상국(other partner countries):앙 골라, 중국, 에리트레아, 이디오피아, 과테말라, 인도네시아, 말리, 니카라과, 나이지리아, 파키 스탄, 스리랑카, 팔레스타인, 남아프리카공화국, 동티모르, 베트남 (15개국) $)^{2)}$

-특히 주요지원대상국에 개발원조의 초점을 맞 춤. 그러나 최근 주요 지원대상국에 대한 양자간 원조 비중은 계속 감소하는 추세

-주요 지원대상 분야: 교육, 보건, 민간부문 개발 (농업부문 중심), 평화구축, 환경, 천연자원개발, $\mathrm{HIV} / \mathrm{ADS}$, 거버넌스 개선, 인권존중, 고용창출 등 ㅁ원조조화 및 원조일치(harmonisation and alignment)에 대해서도 북유럽 국가모임인 Nordic plus 회원국간의 정책대화를 주도하는 등 적극적으로 대응하고 있음.

ㅁ인도적 지원 분야는 노르웨이 개발협력에서 매우 높은 우선순위를 가짐.

- 개발원조정책이 어떻게 평화구축(Peacebuilding)에 기여할 수 있는가에 대한 전략적 틀 을 마련하였으며 기존 인도적 원조 및 장기 개발 원조 수단이 불충분한 상황에 있는 국가를 지원 키 위해 특별예산(A special budget line)을 2002년부터 마련함.

- 인도적 지원과 관련, 노르웨이는 $\mathrm{NGO}$ 에 크게
의존(2002년 기준 전체 원조의 $22 \%$ 를 제공)

ㅁ 개발과정에서 수원국민의 인권을 동시에 고려하 는 정책 (rights-based approach)을 추구함.

-수원국이 빈곤감소전략(PRS) 마련시 인권문제 를 배려토록 지원

-여기에서 인권은 시민 - 정치적 권리와 아울러 경제·사회 · 문화적 권리를 모두 포괄하는 개 념임.

ㅁ 노르웨이 개발 $\mathrm{NGO}$ 는 정부의 지원에 대한 의존도 가 대단히 높음.

- 높은 정부 의존도로 말미암아 노르웨이 $\mathrm{NGO}$ 는 독립적 지위에서 개발정책 및 프로그램 마련에 기여하는 존재가 아니라 정부의 원조프로그램 이행자의 지위로 전락할지 모른다는 우려가 있 는 실정임

\section{3. 개발원조에 대한 정치적 합의 및 국민적 지지}

ㅁ노르웨이에서는 개발원조 수준 및 지원 우선 순위 등에 있어서 강력한 국민적 지지를 받고 있음.

- 구체적인 개발원조 실태에 대한 일반 대중들의

이해는 그다지 높지 않음. 그럼에도 여타 DAC 회원국들 보다는 개발원조 체제에 대해 잘 인식 하고 있는 것으로 평가됨.

\section{4. 원조체계}

ㅁ 주요 대외원조 시행기관 
-외교부 : 25 개 협력대상국(partner countries) 과의 양자차원 원조를 담당하며, 전체 $\mathrm{ODA}$ 예 산의 $80 \%$ 이상을 집행

-노르웨이 개발협력단(NORAD : Norwegian Agency for Development Cooperation) : 외 교부 산하기관으로서 상기 $\mathrm{NGO}$ 를 통한 대외원 조 시행의 감독, 대정부 자문 및 관련분야 연구 업무 등을 담당하며, ODA의 10 15\%를 수행 -노르웨이 평화봉사단(Norwegian Peace Corps) : 외교부 산하단체로서(이사진을 외교부 가 임명) 저개발국과의 인적교류를 담당하고 있 으며, ODA 예산의 $1 \%$ 가량 사용

-NORFUND : 반관반민기관으로서 주식투자 등 을 통한 협력대상국의 산업개발을 목표로 하고 있으며, 2004년도 정부출연금은 총 ODA 예산 의 $3 \%$ 가량

※ 이전에는 NORAD가 양자원조의 시행을 담당하였으 나 2004.4월부터 decentralization 차원에서 이를 외교부-구체적으로는 대상국가 주재 공관-에서 담 당하고 있으며, 이에 따라 NORAD의 역할 및 인원 도 축소(약 $300 \rightarrow 200$ 명)된 바 있음.

ㅁ 상기와 같이 대외무상원조를 다수의 기관이 분담 하여 집행하고 있으나, 외교부에서 효과적으로 조 정역할을 수행하고 있으며, 각 기관간 별도의 상설 화된 협의체는 없음.

ㅁ 노르웨이는 2004년 개발원조체계에 대한 전반적 개편을 단행함.

- 개발원조활동의 기획, 실행기능은 외교부로 이 관됨.
- 그리고 해외공관에 보다 많은 권한을 위임 (delegate)함으로써 의사결정의 분권화 (decentralisation)가 이루어짐.

- NORAD(Norwegian Agency for Development Cooperation)는 사업평가, 원조품질보증, 지식 관리, 그리고 시민사회와 민간부문에 우호적인 무상원조 체제 운영 등으로 담당영역이 변화하 였으며 외교부 내 기술국(Technical directorate) 의 지위에서 외교부와 공관에 자문을 제공함.

ㅁ 이러한 개편은 원조정책, 전략 그리고 실행간 상호 유기적 구성 및 유관부처간 역할분담의 명확화 등 을 목표로 함.

\section{II. 노르웨이 원조내역}

\section{1. 총괄}

ㅁ 노르웨이의 ODA는 $99 \%$ 이상이 무상원조이며 유 상원조로서는 World Bank/IDA에의 기여금이 있 는 바 전체 $\mathrm{ODA}$ 의 $1 \%$ 미만임.

-2004년 기준 노르웨이의 ODA 총 규모는 22 억 불 수준으로서 $\mathrm{GDP}$ 의 $0.87 \%$ 의 비중을 차지하 고 있는 바, 노르웨이 정부는 중장기적으로 $\mathrm{ODA}$ 규모가 $\mathrm{GDP}$ 의 $1 \%$ 에 도달하도록 한다는 방침임.

$\square \mathrm{ODA}$ 의 $50 \%$ 이상은 UN, UNDP, World Bank 등 국제기구를 통하여 $20 \%$ 가량은 국내외 $\mathrm{NGO}$ 를 통하여 집행되고 있음. 


\section{2. 최근 5 년간 노르웨이 ODA 지원규모}

2003년도 ODA 규모: US\$2,042백만(ODA/GNI 비율: $0.92 \%)$

-ODA 총액 기준으로 $\mathrm{DAC} 22$ 개 회원국 중 9위, ODA/GNI 비율 기준으로는 1위임.

-현 정부는 2009 년까지 동 비율을 $1 \%$ 까지 높인 다는 목표를 설정

\begin{tabular}{|c|c|c|c|c|c|c|c|c|c|}
\hline 199 & 99년 & 200 & 00년 & 20 & 01년 & 20 & 2년 & 200 & 3년 \\
\hline ODA & $\begin{array}{l}\text { ODA } \\
\text { /GNI }\end{array}$ & ODA & $\begin{array}{l}\text { ODA } \\
\text { /GNI }\end{array}$ & ODA & $\begin{array}{l}\text { ODA } \\
\text { /GNI }\end{array}$ & ODA & $\begin{array}{l}\text { ODA } \\
\text { /GNI }\end{array}$ & ODA & $\begin{array}{l}\text { ODA } \\
/ G N I\end{array}$ \\
\hline 1,370 & $0.88 \%$ & 1,264 & $0.76 \%$ & 1,346 & $0.80 \%$ & 1,696 & $0.89 \%$ & 2,042 & $0.92 \%$ \\
\hline
\end{tabular}

※ 자료: OECD, The DAC Journal: Development Cooperation 2004 Report

\section{ODA 지원현황}

\section{1) ODA 규모:US\$2,042백만(2003년)}

ㅁ양자간/다자간 $\mathrm{ODA}$

-양자간 ODA 규모: US $\$ 1,462$ 백만(72\%)

- 다자간 ODA 규모: US $\$ 580$ 만(28\%)

※ UN 등 다자기구 지원비중이 비교적 높은 편

※양자/다자/NGO 등 원조제공 채널 선택은 $\mathrm{MDGS}$

및 기타 원조목표 달성에 어느 쪽이 더 비교우위에

있는가를 기준으로 함.

ㅁ양자간 $\mathrm{ODA}$ 중 유·무상 비중

- 무상원조 규모: US\$1,455백만(99.5\%)

-유상원조 규모: US\$580만(0.5\%)

\begin{tabular}{|c|c|c|c|c|c|c|}
\hline 순위 & \multicolumn{2}{|c|}{ 국명 } & \multicolumn{2}{|c|}{$\begin{array}{c}\text { 지원규모 } \\
\text { (2002-2003 평균) }\end{array}$} & \multicolumn{2}{|c|}{$\begin{array}{c}\text { 점유율 } \\
(2002-2003 \text { 평균) }\end{array}$} \\
\hline 1 & \multicolumn{2}{|c|}{ 아프가니스탄 } & \multicolumn{2}{|c|}{65} & \multicolumn{2}{|c|}{$3.5 \%$} \\
\hline 2 & \multicolumn{2}{|c|}{ 탄자니아 } & \multicolumn{2}{|c|}{57} & \multicolumn{2}{|c|}{$3.0 \%$} \\
\hline 3 & \multicolumn{2}{|c|}{ 팔레스타인 } & \multicolumn{2}{|c|}{52} & \multicolumn{2}{|c|}{$2.8 \%$} \\
\hline 4 & \multicolumn{2}{|c|}{ 모잠비크 } & \multicolumn{2}{|c|}{46} & \multicolumn{2}{|c|}{$2.5 \%$} \\
\hline 5 & \multicolumn{2}{|c|}{ 이라크 } & \multicolumn{2}{|c|}{38} & \multicolumn{2}{|c|}{$2.0 \%$} \\
\hline 6 & \multicolumn{2}{|c|}{ 우간다 } & \multicolumn{2}{|c|}{35} & \multicolumn{2}{|c|}{$1.9 \%$} \\
\hline 7 & \multicolumn{2}{|c|}{ 세르비아-몬테네그로 } & \multicolumn{2}{|c|}{33} & \multicolumn{2}{|c|}{$1.8 \%$} \\
\hline 8 & \multicolumn{2}{|c|}{ 이디오피아 } & \multicolumn{2}{|c|}{33} & \multicolumn{2}{|c|}{$1.8 \%$} \\
\hline 9 & \multicolumn{2}{|c|}{ 소말리아 } & \multicolumn{2}{|r|}{33} & \multicolumn{2}{|c|}{$1.7 \%$} \\
\hline 10 & \multicolumn{2}{|c|}{ 잠비아 } & \multicolumn{2}{|c|}{32} & $1.7 \%$ & \\
\hline 합계 & & & & 124 & 22.79 & \\
\hline ※ 자료 & ECD, The & C Jour & al: Developme & t Cooper & ration 2004 Rep & \\
\hline & & 〈상위 & 0대 수원국 본 & |동추이〉 & & \\
\hline 순위 & $\begin{array}{c}\text { 국명 } \\
\text { (1982-83) }\end{array}$ & $\%$ & $\begin{array}{c}\text { 국명 } \\
\text { (1997-98) }\end{array}$ & $\%$ & $\begin{array}{c}\text { 국명 } \\
\text { (2002-03) }\end{array}$ & $\%$ \\
\hline 1 & 탄자니아 & 9.3 & 탄자니아 & 6.6 & 아프가니스탄 & 3.5 \\
\hline 2 & 방글라데시 & 4.8 & 모잠비크 & 5.8 & 탄자니아 & 3.0 \\
\hline 3 & 케냐 & 4.0 & 잠비아 & 3.6 & 팔레스타인 & 2.8 \\
\hline 4 & 인도 & 3.6 & 방글라데시 & 3.1 & 모잠비크 & 2.5 \\
\hline 5 & 모잠비크 & 3.0 & 베넹 & 2.1 & 이라크 & 2.0 \\
\hline 6 & 잠비아 & 2.6 & 니카라과 & 1.9 & 우간다 & 1.9 \\
\hline 7 & 스리랑카 & 2.3 & 짐바브웨 & 1.9 & $\begin{array}{c}\text { 세르비아 } \\
\text { 몬테네그로 }\end{array}$ & 1.8 \\
\hline 8 & 파키스탄 & 2.2 & 구 유고연방 & 1.7 & 이디오피아 & 1.8 \\
\hline 9 & 수단 & 1.9 & 보츠와나 & 1.6 & 소말리아 & 1.7 \\
\hline 10 & 짐바브웨 & 1.5 & 이디오피아 & 1.6 & 잠비아 & 1.7 \\
\hline 합계 & & 35.2 & & 29.9 & & 22.7 \\
\hline
\end{tabular}

※ 자료: OECD, The DAC Journal: Development Cooperation 2004 Report

\section{3)지역별 지원현황(양자간 ODA 기준)}

-지원의 대부분이 사하라 이남 아프리카 지역에 집중되고 있으며 서남아 및 중앙아시아 지역에 도 $15 \%$ 이상의 지원이 유지되고 있음.

\section{2) 10대 수원국}




\begin{tabular}{c|c|c|c}
\hline 지 역 & $1982-83$ & $1992-93$ & 2002-03 \\
\hline 유럽 & 2.8 & 3.4 & 14.4 \\
사하라이북 아프리카 & 0.3 & 0.1 & 0.4 \\
사하라이남 아프리카 & 56.5 & 61.8 & 45.8 \\
북중미 & 2.6 & 7.0 & 4.0 \\
남미 & 0.9 & 2.3 & 2.5 \\
중동 & 2.0 & 1.2 & 10.8 \\
서남아 및 중앙아시아 & 28.5 & 17.7 & 16.8 \\
극동아시아 & 6.0 & 6.4 & 5.2 \\
오세아니아 & 0.4 & 0.0 & 0.0 \\
합 계 & 100 & 100 & 100 \\
\hline
\end{tabular}

※ 자료:OECD, The DAC Journal: Development Cooperation 2004 Report

\section{4) 소득그룹별 지원현황(양자간 ODA 기준)}

ㅁㅊ치비내도국에 $54.2 \%$, 중저소득국에 $32.9 \%$ 를 지 원하고 있음.

\begin{tabular}{c|c|c|c}
\hline 지 역 & $1982-83$ & $1992-93$ & 2002-03 \\
\hline 최빈개도국(LDCs) & 55.0 & 63.0 & 54.2 \\
기타저소득국(other LICs) & 26.9 & 15.9 & 10.0 \\
중저소득국(LMICs) & 13.5 & 16.2 & 32.9 \\
고중소득국(UMICs) & 4.6 & 4.9 & 2.9 \\
고소득국(HICs) & - & - & - \\
MADCT') & - & 0.0 & 0.0 \\
합계 & 100 & 100 & 100 \\
\hline
\end{tabular}

주1):More Advanced Developing Countries and Territories(동 국가에 대한 지원은 OA(Official Aid)로 분류)

※자료: OECD, The DAC Journal: Development Cooperation 2004 Report, Table 32

\section{5) 2003년도 노르웨이 분야별 지원실적}

-사회 및 행정인프라 $41.2 \%$, 긴급원조 (Emergency aid) $23.8 \%$, 다부문 $9.2 \%$, 경제인 프라 $7.6 \%$, 생산 $4.5 \%$ 등

-사회 및 행정인프라는 10 여년 전에는 $19.6 \%$, 긴 급원조는 $7.0 \%$ 에 머물렀던 것이 최근에 이르러 그 비중이 크게 상승한 점이 주목할 만함.

\begin{tabular}{|c|c|c|}
\hline \multicolumn{2}{|l|}{ 분 야 } & 2003년도 \\
\hline $\begin{array}{c}\text { 사회 및 행정 인프라 } \\
\text { (Social and administrative } \\
\text { infrastructure) }\end{array}$ & $\begin{array}{c}\text { 교육(기초교육) } \\
\text { 보건(기초보건) } \\
\text { 인구 } \\
\text { 식수 및 위생 } \\
\text { 정부 및 시민사회 } \\
\text { 기타 사회인프라/서비스 }\end{array}$ & $\begin{array}{c}9.1 \%(4.8 \%) \\
6.7 \%(3.5 \%) \\
2.4 \% \\
1.4 \% \\
15.4 \% \\
6.2 \%\end{array}$ \\
\hline 소 계 & & $41.2 \%$ \\
\hline $\begin{array}{c}\text { 경제인프라 } \\
\text { (Economic infrastructure) }\end{array}$ & $\begin{array}{c}\text { 교통 및 통신 } \\
\text { 에너지 } \\
\text { 기타 }\end{array}$ & $\begin{array}{l}1.7 \% \\
4.2 \% \\
1.7 \%\end{array}$ \\
\hline 소 계 & & $7.6 \%$ \\
\hline $\begin{array}{c}\text { 생산 } \\
\text { (Production) }\end{array}$ & $\begin{array}{c}\text { 농업 } \\
\text { 제조업, 광업 및 건축 } \\
\text { 무역 및 관광 }\end{array}$ & $\begin{array}{l}3.9 \% \\
0.1 \% \\
0.6 \%\end{array}$ \\
\hline 소 계 & & $4.5 \%$ \\
\hline $\begin{array}{r}\text { 다부문(Multise } \\
\text { 프로그램원조(Programm } \\
\text { 부채탕감(Action relati) } \\
\text { 긴급원조(Emerger } \\
\text { 행정경비(Administrati) } \\
\text { 기타(Unspecif }\end{array}$ & $\begin{array}{l}\text { assistance) } \\
\text { to debt) } \\
\text { aid) } \\
\text { expenses) }\end{array}$ & $\begin{array}{c}9.2 \% \\
3.6 \% \\
1.5 \% \\
23.8 \% \\
6.8 \% \\
1.7 \%\end{array}$ \\
\hline 합 계 & & $100 \%$ \\
\hline
\end{tabular}

※ 자료: OECD DAC Journal: Development Cooperation 2004 Report, Table 19

\section{ODA 조직운영 동향}

1. 노르웨이 정부는 빈곤감소 목표를 효과적으로 달성하기 위하여 2004년 원조조직 개편을 단행

-노르웨이 외교 및 개발관련 기획, 실행, 행정 업 무는 외교부로 통합

-수원국 주재 외교공관에 개발 프로그램 실행의 책임을 대폭 위임함으로써 의사결정을 분권화 시킴.

- NORAD(Norwegian Agency for Development Cooperation)는 원조사업의 평가(Evaluation), 
외교부 및 해외공관에 대한 기술자문 제공, 원조품

질보장 등의 임무를 맡음. $\mathrm{NORAD}$ 의 최고책임자 (Director)는 외교부의 국제개발정책과에 보고함.

\section{2. 외교부:노르웨이 개발협력의 중심기구}

-노르웨이 외교부는 2 인의 장관(외무장관, 개발 장관)과 1 인의 사무총장을 둠. 사무총장은 2 인의 장관 모두를 보좌함.

-외교부 내에는 10 개 과가 설치됨(과거 11 개에서 축소됨). 이 중 개발협력 주무부서는 국제개발정 책과(DIDP)로서 개발원조, 다자개발, 주요 원조 우선 순위 등을 다루고 원조조화/일치 업무를 관장

-타 부서들도 개발원조 유관영역에 관계될 경우 개발협력분야에 관여함.

- 본부는 매년 해외공관의 연간 개발원조 활동계 획을 승인

- 인도적 지원(managing humanitarian action) 과 관련, 외교부는 '인권, 민주주의, 인도적지원 담당과 를 신설함. 이로 말미암아 원조체계가 다소 복잡해지고 부처간 상호공조 비용이 상승 하는 문제가 생김.

\section{NORAD의 역할변경}

\section{1) 평가부문}

-2004년까지 개발원조사업 평가업무에 외교부, $\mathrm{NORAD}$ 및 기타 유관부처 등 서로 다른 기관들 이 동시에 참여하고 있어서 체계가 복잡하고 많 은 비용이 소모되는 문제가 있었음.
- $\mathrm{NORAD}$ 는 외교부 직제개편 후, 동 기관 내의 사업평가과(Evaluation Department)에서 모든 개발원조사업의 평가 및 개발연구(development research, 예컨대 빈곤, 보건, 분쟁, 평화구축 등)를 담당하게 됨. 이는 국별 차원에서의 정책 및 관여에 대한 평가활동이 독립성을 갖게 된 것 으로 볼 수 있음.

-아울러 $\mathrm{NORAD}$ 는 사업평가와 관련, 다음의 역 할을 수행함.

(1) 평가결과 체계화 (2)국제적 차원에서의 개발 협력 평가기관 및 네트워크와 상호협력 (3)다수 공여국이 관여하는 평가활동에 참여 (4)개발협 력 연구기관과의 연계

\section{2) 기술자문 부문}

- 조직개편 후 $\mathrm{NORAD}$ 는 다자기구를 통해 지원 되는 사업 및 정책보고서에 대한 기술자문 기능 을 맡게 됨.

- NORAD는 다음의 4 개 부서를 통해 동 역할을 수행:환경 및 민간부문 개발과, 인적자원 및 서 비스 제공 담당과, 거버넌스 및 거시경제담당과, 원조품질보증 담당과

\section{3) 원조품질보증 및 지식관리}

-NORAD는 원조품질보증(Guality assurance and knowledge management) 기능을 수행. 이를 위해 (1)해외 현지공관에 대한 권한 위임 관 련 지원 제공 (2)사업방식 및 제도 개선 (3)평가, 기록, 그리고 결과의 확산을 위한 수단 개발 
- 노르웨이 정부는 평가, 원조품질보증, 그리고 지 식관리 기능을 $\mathrm{NORAD}$ 내에 결합시킴으로써 모니터링 및 평가에 있어서 원조일관성 및 상호 공조 개선을 추구하고 서로 다른 차원에서의 결 과를 체계화 하고자 하고 있음.

\section{4) 원조결과 관리}

- 외교부는 조직개편시 원조결과 관리 문제를 염 두에 둠.

- NORAD가 개발원조 평가업무 전반에 책임을 지게 되는 한편, 원조결과관리는 외교부에서 담 당함. 이 역할분담은 각 기관이 역량을 집중할 수 있는 기회를 제공하는 반면, 원조사업 평가결 과를 향후 정책수립 및 집행 등에 반영하는 데는 한계를 노정하고 있음. 따라서 향후 두 기관의 정보공유 및 지식관리 성과에 따라 조직개편의 성공여부가 영향을 받게 될 것임.

\section{5) 인적자원 관리}

- 조직개편에 따라 외교부 본부, NORAD, 그리고 해외공관 간에 인력 재배치가 이루어 짐. $\mathrm{NORAD}$ 의 경우 약 $60 \sim 70$ 명 정도의 인원이 감 축되며 그 중 50 명이 외교부로 흡수됨. 35 명은 해외공관으로 이전될 예정. 그 결과 외교부 본부 는 239명, 공관에는 198명, NORAD에는 190명 의 직원이 배치됨. 전반적으로 $\mathrm{NORAD}$ 에서 외 교부 및 공관으로 인력이 이동되고 전체 인력의 증감은 별로 없는 편

- 이상의 외교부 개편에 따른 성과는 아직 분명치
않은 단계임.

\section{4. 기타 개발원조에 관여하는 기관}

ㅁ외교부가 개발협력의 주도적인 역할을 맡고 있으 나 여타 유관 부처들도 함께 개발원조에 참여함.

-Storting's 상설외교위원회:외교부와 함께 노르 웨이 정책 전반에 양립할 수 있는 개발협력정책 수립

-재무부:IMF 및 노르웨이 중앙은행과의 관계유 지 관련 임무를 맡고 있음.

-감사원:개발협력 관련 재원이 어떻게 쓰이고 있 는지 정기적으로 보고함.

- 기타 환경부, 보건부, 교육부 등이 개발협력정책 에 관여하고 있음.

\section{2005년 동료평가 권고사항}

\section{1. 개발전략}

- 인권중심적 개발협력 접근방식을 실행에 옮길 때 우선 순위 수원국과의 정책대화가 어떤 영향 을 받게 되는지를 고려할 것

-노르웨이의 원조조직 개편 경험을 공유함으로 써 타 공여국들이 도움을 받을 수 있을 것임.

- 개발결과를 강조하는 현재의 기조를 유지할 것 (특히 섹터별 지원 및 예산지원 분야). 이는 일반 대중의 개발협력에 대한 지지를 강화하는데 도 움이 될 것임.

-양성평등 분야에 대한 관심을 유지토록 함. 


\section{2. 원조규모 및 배분}

-ODA/GNI $1 \%$ 목표에 근접하려는 노력을 높이 평가하며 다년주의 원조재원 제공방식을 도입 하여 수원국들에게 원조재원 유입규모의 예측 가능성을 제고토록 할 것을 권고함.

-장기로 지원되는 원조 및 노르웨이가 비교우위 를 갖는 원조제공 방식을 모색할 것을 권고함.

-정부와 NGO 간의 관계를 다룰 전략을 마련할 필요가 있음. 대 $\mathrm{NGO}$ 지원 기준을 명료화하는 한편, $\mathrm{NGO}$ 가 빈곤감소에 얼마나 기여하는지 평가하는데 더 많은 노력을 기울일 필요 있음.

\section{3. 개발정책일관성}

- 정책일관성 향상을 위한 정부의 조치에 관해 정기 적으로 보고하고 $\mathrm{MDGs}$ 를 유관 정부 정책에 통합 시킬 수 있는 가능성을 탐구할 것을 권고함. 또한 그 분야를 포괄하는 전체 정부차원 메커니즘을 마 련하여 정책일관성을 강화할 수 있을 것임.

- 개편된 $\mathrm{NORAD}$ 에서 정책일관성 관련 정책에 대한 평가가 향후 가능할 것임.

\section{4. 원조관리 및 실행}

-노르웨이 정부는 해외공관이 어떻게 인권에 기 초한 개발접근방식을 실행에 옮길 것인지 그 방 안을 명료화시켜야 함.

-노르웨이 정부는 원조관련 행정에 있어서 적절 한 인력과 자원을 결합하여 주요 개발원조정책 분야에 대한 자문 및 지원을 제공해야 함. 또한 양성평등 분야에 대한 지지를 강화해야 함.

-정부는 $\mathrm{NORAD}$ 가 새로이 맡은 기능과 역할을 잘 수행할 수 있도록 적절한 자원을 제공해야 함.

\section{5. 인도적 지원}

-정부는 인도적 지원 관련 포괄적 정책문서를 발 간하는 방안을 검토하기를 권고함. 여기에는 자 연재난에 대한 대처방안이 포함됨. 동 문서 발간 을 통해 인도적 지원 관련 기존의 원칙과 모범관 행과의 일관성을 확보함.

-노르웨이 정부는 최적화된 인도적 지원활동을 위해 정부부처간, 그리고 부처 내 상호협력이 이 루어 지도록 해야 함. 


\section{노르웨이 외무부 조직도}

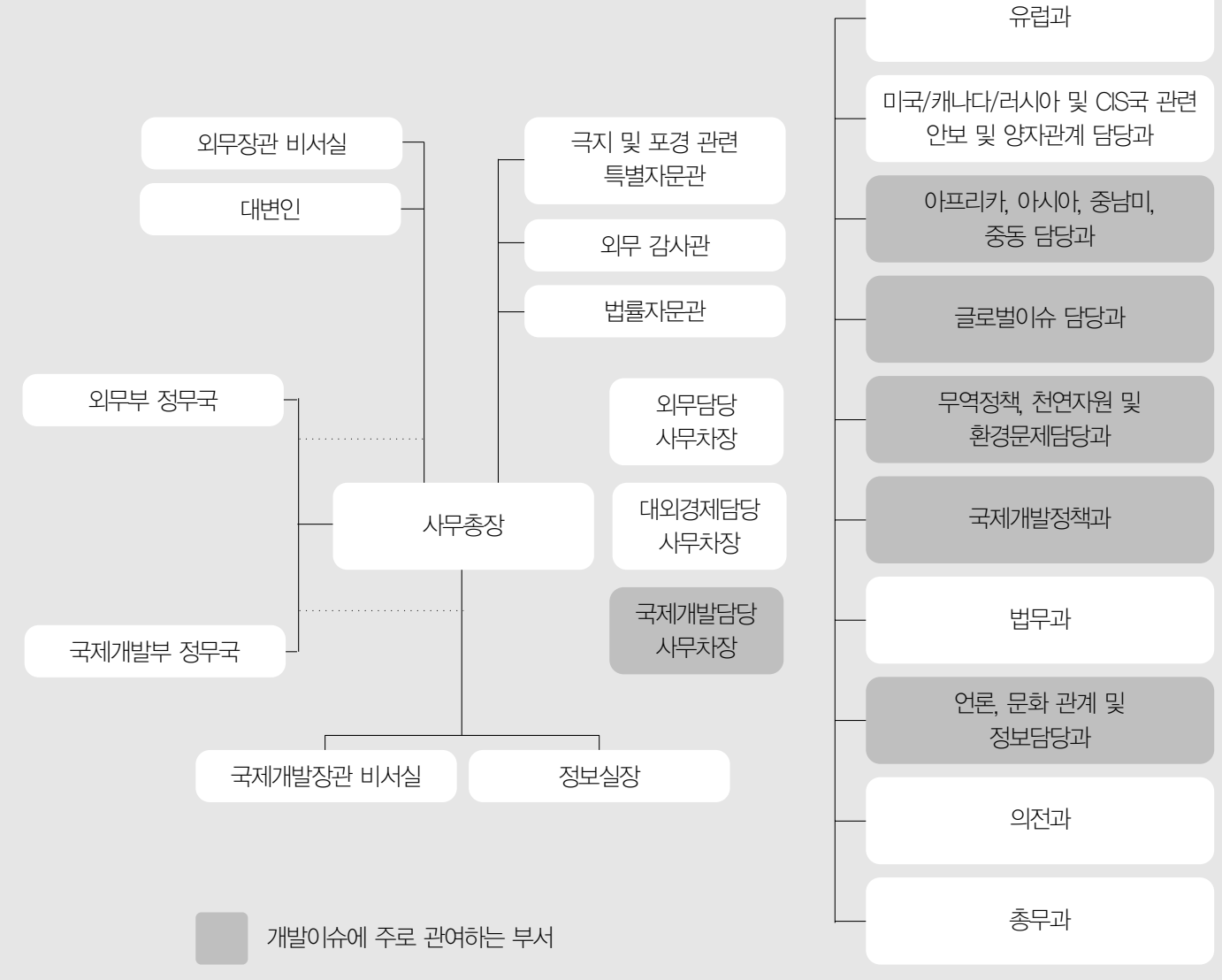

\section{NORAD 조직도}

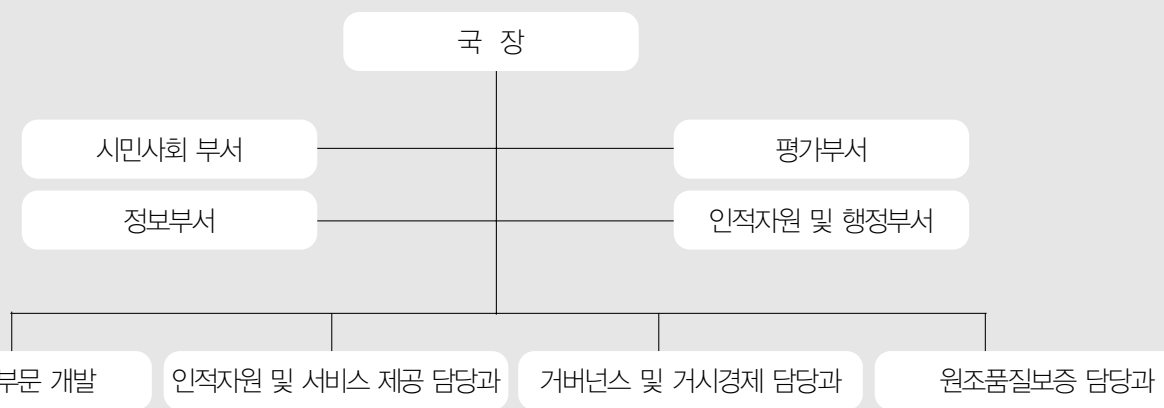

\section{유럽과}

원조품질보증 담당과 